\title{
CAPITAL INTELECTUAL COMO RECURSO NA RETENÇÃO DE CLIENTES
}

\author{
INTELLECTUAL CAPITAL AS A RESOURCE IN CUSTOMER RETENTION
}

Recebido em 22.02.2015. Aprovado em 21.09.2015

Avaliado pelo sistema double blind review

DOI: http://dx.doi.org/10.12712/rpca.v9i3.542

\section{Fernando Luís Bertolla}

fernando@cruzeiro.inf.br

Universidade de Caxias do Sul, Caxias do Sul/RS, BRASIL

\section{Alex Eckert}

prof.alex.eckert@gmail.com

Universidade de Caxias do Sul, Caxias do Sul/RS, BRASIL

\section{Eric Charles Henri Dorion}

echdorion@gmail.com

Universidade de Caxias do Sul, Caxias do Sul/RS, BRASIL

\section{Cristine Hermann Nodari}

cristine.nodari@gmail.com

Universidade Potiguar, Natal/RN, BRASIL

\section{Resumo}

Este ensaio teórico explorou a possibilidade de relação teórica entre o capital intelectual e a retenção de clientes, com moldura teórica na perspectiva contábil da teoria baseada no conhecimento (knowledge based theory), dos ativos de conhecimento. Foram exploradas as relações entre os elementos e indicadores do capital intelectual: humano, estrutural e relacional, com a retenção de clientes segundo as tipologias das táticas vinculantes: sociais, financeiras e estruturais. Como resultados, apresentou-se um framework ressaltando as relações existentes com intuito, de incentivar a aplicabilidade empírica através da utilização de técnicas de análise multivariada de dados, propiciando, assim, um aperfeiçoamento nas pesquisas que lidam com a subjetividade desta mensuração, como observado nas mensurações contábeis tradicionais.

Palavras-chave: Ativos de Conhecimento. Capital Intelectual. Retenção de Clientes. Táticas Vinculantes.

\begin{abstract}
This theoretical essay explored the possibility of theoretical relationship between intellectual capital and customer retention, with theoretical framework in accounting theory perspective based on knowledge (knowledge based theory), the knowledge assets. The relationships between the elements and indicators of intellectual capital were explored: human, structural and relational, with customer retention according to the types of binding tactics: social, financial and structural. The results, presented a framework highlighting the relationships with the aim of encouraging empirical applicability through the use of multivariate data analysis techniques, providing thus an improvement in research dealing with the subjectivity of this measurement, as seen in traditional accounting measurements.
\end{abstract}

Keywords: Knowledge Asset. Intellectual Capital. Customer Retention. Tactics binding. 


\section{Introdução}

Ao afirmar que o conhecimento não é privado, mas, social, Polanyi (1966) busca enfatizar que este é, socialmente, construído e tem como base a experiência pessoal de cada indivíduo sobre a realidade em que está inserido. Sob a perspectiva de inserção da realizade das organizações, Senker (1995) destaca a inovação, como força motriz das mudanças organizacionais, e, que ocorre através da combinação de novos processos, produtos ou serviços. Cerca de um terço do conhecimento aplicado nessas combinações provém de fontes externas, enquanto que os restantes dois terços dividem-se entre o conhecimento da formação dos colaboradores e os resultados de investimentos em pesquisa e desenvolvimento.

Para Stewart (1998) o capital intelectual é a soma do conhecimento de diferentes elementos em uma empresa, o que the proporciona vantagem competitiva, como, por exemplo, na possibilidade de demandar apoio à gestão mais eficiente de seus ativos intangíveis no apoio corporativo proporcionando informações assertivas do ponto de vista econômico financeiro (LÓPEZ-RUIZ et al., 2014; KHALIQUE et al., 2013). Erickson e Rothberg (2000) comentam que o capital intelectual é o estoque de conhecimento de uma organização, originado pela transformação do conhecimento tácito em explícito que pode ser aumentado através da sistematização e estocagem do conhecimento dos indivíduos. Estes conhecimentos estocados se originam das comunicações e relacionamentos entre os indivíduos envolvidos nos processos organizacionais, tais como: funcionários, clientes e fornecedores.

Estas comunicações e relacionamentos também são alvo de outra corrente de estudiosos, atualmente. Os estudos investigativos na área de retenção de clientes (WALTHER et al., 2013; SEQUEIRA et al., 2012; BAIRI e MANOAR, 2011), no decorrer da última década, têm direcionado seus esforços no sentido de compreender de que maneira ocorrem os relacionamentos entre clientes e fornecedores. Neste sentido, diversos modelos ou teorias foram desenvolvidas e testadas, levando a novos achados sobre o assunto. Morgan e Hunt (1994), por exemplo, desenvolveram a Teoria do Compromisso-Confiança (The Commitment-Trust Theory), na qual eles argumentam que o compromisso e a confiança exercem um papel fundamental quando se trata de relacionamentos entre clientes e fornecedores.
Nesta pesquisa, os conceitos antecedentes (custos do término do relacionamento, benefícios do relacionamento, valores compartilhados, comunicação e comportamento oportunista) estariam interligados aos consequentes (aquiescência, propensão para deixar o relacionamento, cooperação, conflito funcional e incerteza). Esta ligação seria realizada por meio dos construtos compromisso (ou comprometimento) e confiança, os quais exercem a função de variáveis mediadoras (MORGAN; HUNT, 1994).

Segundo Johnson e Selnes (2004), estudos realizados sugerem benefícios econômico-financeiros provenientes da retenção de clientes. Assim, o aumento de $5 \%$ na retenção de clientes poderia gerar um aumento na lucratividade de uma empresa entre 25\% e 85\% (REICCHELD, 1996). Ou que, um aumento de $1 \%$ sobre a taxa de retenção de clientes poderia repercutir em um acréscimo de $5 \%$ no valor patrimonial das empresas (GUPTA; LEHMANN; STUART, 2004). A relevância da associação teórica, do ponto de vista prático, estabeleceria de uma forma menos subjetiva, caminhos para dificuldade de mensuração e articulação do capital intelectual por parte da contabilidade no valor econômico do patrimônio das organizações.

Sendo assim, a proposta deste ensaio teórico foi de transitar pela teoria da firma, segundo Machlup (1967) e Grant (1996), e da economia baseada no conhecimento, conforme Drucker (1969) e pelos conceitos de capital intelectual, conforme Brooking (1996) e Edvisson e Malone (1998), classificado como ativo intangível segundo Sveiby (1998) pertencente à área da gestão do conhecimento de acordo com Polanyi (1966), Nonaka e Takeuchi (1995) e Davenport e Prusak (1998). Ainda, abordou e procurou associar a retenção de clientes conforme Morgan e Hunt (1994), Vavra e Pruden (1995), Grönroos (2009), e pelas táticas vinculantes sociais, financeiras e estruturais, segundo Berry e Parasuraman (1991) e Liang e Wang (2008) articulando essas relações de forma a torná-las menos subjetivas. A orientação da análise da relação teórica se dá a partir da economia baseada no conhecimento e os ativos intangíveis, sob a ótica do capital intelectual, que pode ser considerado um recurso que promove a retenção de clientes, sob as tipologias das táticas vinculantes.

Além desta seção introdutória, o documento está dividido em três seções. No referencial teórico, 
abordou-se as ideias seminais e documentos atuais sobre os temas. Após, foram apresentadas as discussões, onde procurou-se reunir e articular semelhanças, distinções e relações a fim de compor o framework de análise. Por fim, foram apresentadas as considerações finais, destacando as oportunidades de trabalhos futuros.

\section{Referencial Teórico}

\section{Teoria da firma e a economia baseada em conhecimento}

Para Machlup (1967) a teoria da empresa é a construção de uma abstração de uma situação real que é desenvolvida para resolver um conjunto particular de características e comportamentos. Segundo Grant (1996), a mensuração de ativos de conhecimento é um assunto pertinente, pois na área da contabilidade, os mecanismos de mensuração que foram desenvolvidos durante a economia industrial, foram baseados em ativos tangíveis e do capital sujeito a propriedade. Assim uma nova teoria da empresa se faz necessária para abordar os ativos de conhecimento, já que existe uma lacuna entre o valor de mercado e o valor contábil das organizações o que torna um problema a ser solucionado pelos pesquisadores da área contábil (TREVIÑO, 2012; BENGOA e KAUFMANN, 2014; LÓPEZ-RUIZ et al., 2014).

O desenvolvimento de uma nova teoria da empresa deve levar em conta que atualmente as organizações estão enfrentando constantes mudanças e incertezas. A empresa de conhecimento, conforme Nonaka e Takeuchi (1995) fornece rápidas respostas às alterações no ambiente e atua mais como um organismo vivo do que como uma máquina. Assim as organizações podem ser concebidas e entendidas se forem comparadas com outros organismos vivos. Esta abordagem para a empresa é válida, pois lida com a complexidade e a incerteza de organizações, mercados, e economias de uma forma mais realista. Grant (1996) em seus estudos comenta que existem várias abordagens de pesquisa que consideram conhecimento como uma questão central: a aprendizagem organizacional, gestão da tecnologia, e cognição gerencial. Também afirma que a teoria da firma baseada em conhecimento tem por objetivo ir além dos conceitos tradicionais, como por exemplo: a coordenação dentro da empresa, à estrutura organizacional, a tomada de decisão, os limites e a inovação.
Drucker (1969) previu o alvorecer da economia do conhecimento com base em uma descontinuidade dos meios de produção, onde é percebida a evolução de organizações, economias e sociedades. Os empresários têm que alocar esse recurso intangível e tomar decisões econômicas com base nele, embora não sendo capaz de compreendê-lo totalmente. Conforme Spender (1996), as organizações precisam de novo quadros de gestão para que assim possam mensurar os ativos de conhecimento. Para construir a teoria do conhecimento da empresa não é fácil, pois existe a necessidade de distinguir e reconhecer os recursos baseados em perspectivas e pontos de vista de evolução. Segundo o Manual de Oslo (1997), a economia baseada no conhecimento é uma expressão que descreve as tendências no sentido de uma crescente dependência de conhecimento e informação. Este novo paradigma desafia as teorias econômicas tradicionais, exige novas construções e a proposição de novos modelos.

Um desenvolvimento econômico paralelo é o aumento da inovação em serviços nas economias evoluídas (DEN HERTOG, et al., 2010). Ordanini e Parasuraman (2011) propõem que as competências de colaboração, capacidade dinâmica de orientação para os clientes e interfaces de conhecimento são fatores chave para as organizações.

Assim, conforme Boisot (1998) e Hendriksen e Van Breda (1999) os ativos de conhecimento considerados como um estoque de fatos, habilidades, hábitos e atitudes de onde os serviços deverão fluir numa trajetória de longa duração podem ser contemplados como potenciais fluxos de serviço ou direitos a benefícios futuros sob o controle e vantagem competitiva da organização.

\section{Ativos de Conhecimento}

Davenport e Prusak (1998) comentam que o conhecimento é adquirido através da experiência e que permanece em sua forma tácita, e, nem sempre pode ser expressado através da linguagem, nem incorporado em ferramentas cognitivas, tais como documentos. Ainda, indicam que não basta considerar o conhecimento a partir da perspectiva de um indivíduo, mas também como um ativo organizacional. Em outras palavras, só é possível adquirir conhecimento quando o indivíduo se encontra em contato direto com situações que 
proporcionam experiências inéditas, que são sempre assimiladas a partir dos conceitos do indivíduo (GROPP e TAVARES, 2009).

Conforme Polanyi (1966), no momento em que novos conceitos ou palavras são inseridos no sistema de linguagem existente, acabam por influenciar mutuamente, pois agregam a este sistema, novos conceitos. Nonaka e Takeuchi (1995) agregam à dimensão epistemológica do conhecimento tácito, a dimensão de gestão, a comunicação e a integração das particularidades. Davenport e Prusak (1998) destacam o papel cognitivo do sujeito conhecedor também para o conhecimento explícito. Os autores destacam o que Polanyi (1966) denominava como "ferramentas cognitivas", ou seja, elementos explícitos como representações abstratas, documentos, rotinas, dentre outros que visam permitir a ação humana intencional, mas que não podem ser interpretadas per se. Essas ferramentas cognitivas exigem o julgamento pessoal de um agente humano, um leitor especializado, que as relaciona e as aplica ao mundo. Estes diversos elementos, que podemos designar como formadores das estruturas cognitivas estão incorporados nos indivíduos, definindo assim a forma de agir e de se comportar, constituindo um filtro através do qual percebem a realidade. Com dificuldade de serem articulados por palavras, os elementos de ordem cognitiva acabam moldando a forma como percebemos o mundo e seus significados.

A perspectiva da contabilidade baseada em ativos de conhecimento e capital intelectual pode ser entendida por buscar explicar as definições dos termos: ativo e capital. Os ativos são recursos econômicos controlados por uma organização cujo custo no momento de aquisição pode ser medido. Ainda conforme Malhotra (2003), que constatou em suas pesquisas com contabilistas, que a avaliação de ativos em geral é um processo subjetivo de modo especial para os ativos intangíveis: que correspondem a ativos de capital que não tem existência física, em que o valor é limitado pelos direitos e benefícios que, antecipadamente, sua posse confere ao proprietário (KOHLER, 1997) que, portanto, correspondem a gastos de organização, marcas, pesquisa e desenvolvimento, direitos de autoria, patentes dentre outros. Dessa forma, surge a apreensão do conhecimento, das experiências aplicadas e tecnologias organizacionais únicas na organização que determinam, portanto, o capital intelectual, como possibilidade de vantagem competitiva.

\section{Capital Intelectual como Recurso}

A partir dos anos 90, as discussões sobre o capital intelectual nas organizações começaram a se intensificar. A literatura sobre capital intelectual tem como seus pesquisadores pioneiros, Brooking (1996), Edvinsson e Malone (1998) e Sveiby (1998). A classificação do capital intelectual, conforme Brooking (1996) destacava quatro agrupamentos principais: i) Ativos de mercado que correspondiam ao potencial da empresa em decorrência dos intangíveis relacionados ao mercado: marca, clientes, lealdade dos clientes, negócios recorrentes, negócios em andamento e canais de distribuição; ii) Ativo humano que correspondia ao benefício gerado, pelos indivíduos, para as organizações por meio da sua expertise, criatividade, conhecimento, habilidade para resolver problemas, tudo visto de forma coletiva e dinâmica; iii) Ativos de propriedade intelectual que correspondem aos ativos que necessitavam de proteção legal para proporcionarem às organizações benefícios, como, por exemplo, know-how, segredos industriais, copyrigth, patentes e design, e; iv) Ativos de infraestrutura que correspondiam à tecnologia, metodologia e processos empregados como cultura organizacional, sistema de informação, métodos gerenciais, aceitação ao risco e banco de dados de clientes.

Conforme Brooking (1996), o capital intelectual não é uma novidade, pois já estava presente desde o momento que o primeiro vendedor estabeleceu uma boa relação com um cliente, o que mais tarde foi denominado de fundo de comércio. No transcurso das últimas décadas, houve um desenvolvimento nas áreas da comunicação e da tecnologia da informação, que acabaram proporcionando novas ferramentas para a construção de uma economia global. Muitas destas ferramentas possuem benefícios intangíveis que antes não existiam, porém agora diversas organizações não conseguiriam sobreviver sem a sua utilização. As propriedades destas ferramentas proporcionam vantagem competitiva e, consequentemente, se constituem em um ativo. Ainda, o capital intelectual é a combinação de ativos intangíveis, fruto das mudanças nas áreas de tecnologia da informação e nos meios de comunicação, que trazem benefícios intangíveis para as entidades e que capacitam o seu funcionamento.

$\mathrm{Na}$ classificação do capital intelectual de Edvinsson e Malone (1998) encontrou-se dois agrupamentos centrais: i) Capital humano que corresponderiam a 
combinação de conhecimento, habilidades, capacidade de inovação e capacidade dos empregados em desenvolver tarefas, elementos de valores, cultura e filosofia empresarial, e; ii) Capital estrutural que corresponderiam a estrutura organizacional, hardware, software, banco de dados, patentes, marca e tudo mais que dá suporte para a produtividade dos empregados e dos clientes incluindo as relações desenvolvidas com eles.

Para Edvinsson e Malone (1998), o capital intelectual é a posse do conhecimento, das experiências aplicadas e tecnologias organizacionais, relacionamentos com clientes e habilidades profissionais que proporcionam à empresa uma vantagem competitiva no mercado em que atuam. Uma definição sobre capital intelectual que se tornou clássica destes autores seminais foi de empregarem o uso da metáfora da árvore, onde sua parte visível: troco, galhos e folhas são bens que as demonstrações contábeis evidenciam, já, a parte oculta da árvore, as raízes, é o que seria o capital intelectual que são os fatores que embasam a empresa visível dando sustentação e robustez.

Sveiby (1998) justificando a criação de um modelo de avaliação para o ativo intangível, denominado "monitor de ativos intangíveis", abre uma possibilidade para a mensuração dos ativos intangíveis, principalmente do capital intelectual, classificando três agrupamentos principais: i) Estrutura externa relacionada à marca, relações com clientes, fornecedores e imagem da empresa; ii) Estrutura interna que correspondia a estrutura organizacional, gerencial e legal, sistemas, pesquisa e desenvolvimento, e; iii) Competência individual que correspondia a capacidade de agir em diversas situações para criar ativos tangíveis e intangíveis.

Sveiby (1998) considera as pessoas como únicos e verdadeiros agentes na empresa e que os ativos tangíveis e intangíveis são resultado das ações humanas que criam as estruturas internas e externas. Da mesma forma, o autor demonstrou, através da figura 1, as ligações entre os ativos intangíveis de uma organização e sua fragmentação dentro da perspectiva de criação de valor. Assim, para Sveiby (1998), o valor de mercado de uma empresa é formado por ativos tangíveis denominados de capital financeiro e por ativos intangíveis representados pelo capital intelectual. Segundo Stewart (1998) o capital intelectual é composto pelas capacidades, conhecimentos, habilidades e experiências dos empregados e dos gerentes. Inclui-se também a criatividade e a inovação organizacional, observando com que frequência as novas ideias são geradas dentro da empresa e com que frequências essas ideias são implementadas, bem como o sucesso nas suas implementações.

Figura 1 . Estrutura de formação dos Ativos Intangíveis

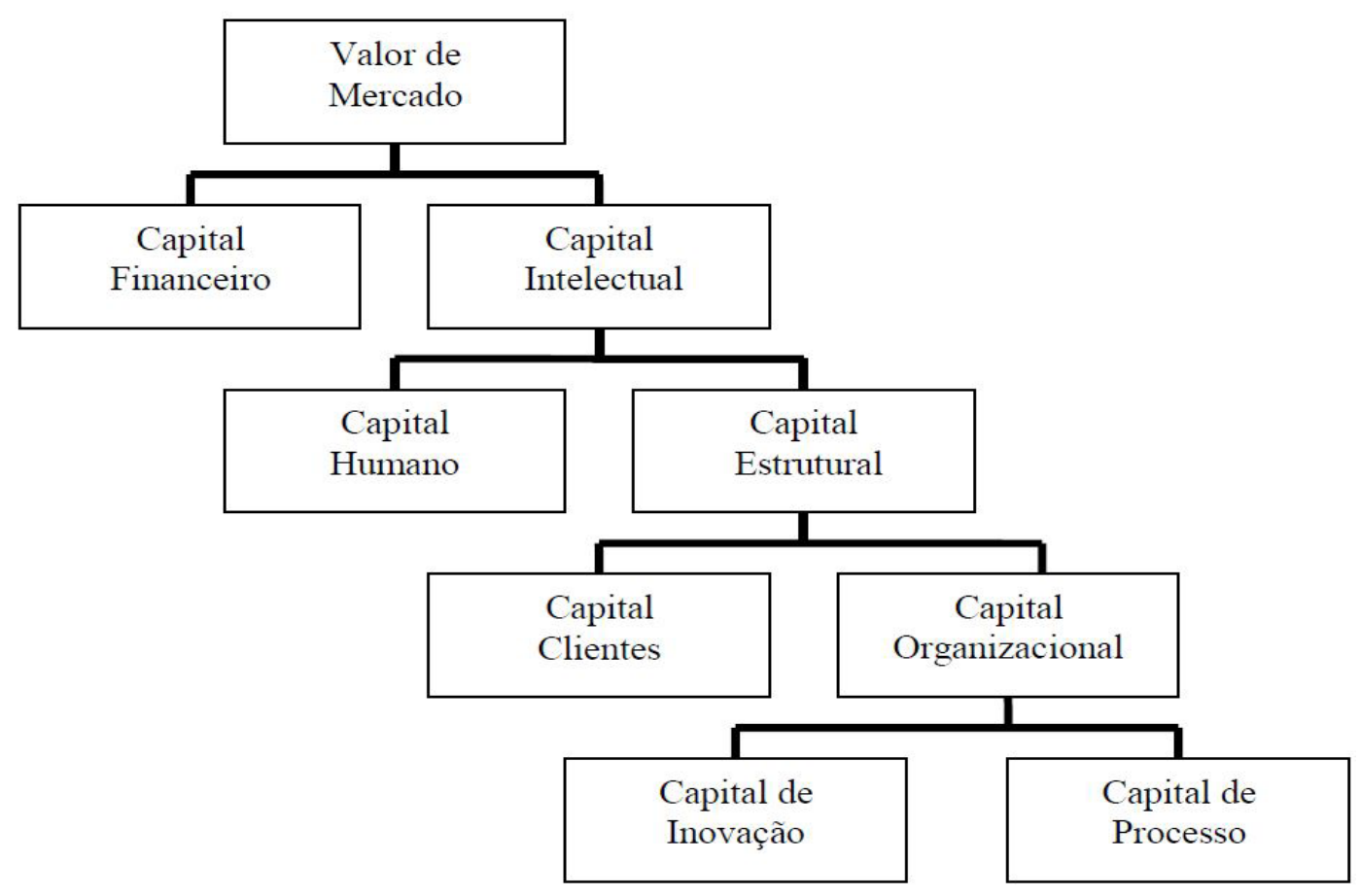

Fonte: Adaptado de Sveiby (1998). 
Para Bontis (2001) o capital humano é considerado como um dos componentes do capital intelectual e concebe o conjunto das competências, inovações, valores, cultura organizacional, políticas e filosofias de trabalho. Através de suas pesquisas empíricas, Pereira (2004) explicita os elementos e indicadores relacionados com o desenvolvimento do capital intelectual, ainda separados em suas divisões mais comuns: capital humano, estrutural e relacional, conforme figura 2.

Figura 2 . Indicadores relacionados com o desenvolvimento do Capital Intelectual

\begin{tabular}{|c|c|c|}
\hline Capital Humano & Capital Estrutural & Capital Relacional \\
\hline Educação Formal & Uso Efetivo do Conhecimento Existente & Lealdade dos Clientes \\
\hline Espírito Empreendedor & $\begin{array}{c}\text { Mecanismos de Transmissão do } \\
\text { Conhecimento } \\
\text { Conhecimento Técnico }\end{array}$ & $\begin{array}{c}\text { Alinhamento Conhecimento com a } \\
\text { Canais de Distribuição }\end{array}$ \\
\hline Know-how / Experiência & Cultura Corporativa / Organizacional & Parcerias \\
\hline Habilidade de Liderança & Propriedade Intelectual & Clientes \\
\hline Espírito de Time & Marcas e Patentes & Faturat share \\
\hline Estabilidade & Ativos de Infra-estrutura & Duração do Relacionamento com \\
\hline Habilidade de Planejamento & Filosofia da Gestão & Satisfação dos Clientes \\
\hline Satisfação / Motivação & Processos & Investimento em Pós-venda \\
\hline Investimento em Treinamento & Situação Financeira & Ranking de Clientes \\
\hline Baixa Rotatividade & Sistemas de Informação & Relacionamento com Fornecedores \\
\hline Quantidade de Funcionários com & Custo do Erro Administrativo & Alianças Estratégicas \\
\hline Dedicação Exclusiva & Investimento em Tecnologia da Informação & Eficiência da Estrutura Organizacional \\
\hline
\end{tabular}

Fonte: Adaptado de Pereira (2004).

Com vista na classificação destes elementos, observam-se que muitas empresas já estão experimentando diferentes maneiras de se relacionar com os clientes, objetivando tornar estes relacionamentos mais produtivos e duradouros. Estas iniciativas podem, muitas vezes, exigir da empresa uma estratégia coordenada de esforços em toda a cadeia de valor (CANNON; PERREAULT Jr., 1999). Ao fornecedor, cabe a conquista de seus clientes e garantia de sua permanência na empresa, criar vínculos mais fortes com seus clientes, fazer com que os mesmos se sintam satisfeitos e envolvidos com a empresa (OLIVER, 2010), e que construam uma resistência à mudança de provedor de serviços (PETRICK, 2004; HENNIG-THURAU; GWINNER; GREMLER, 2000; 2002).

Essa maneira de se relacionar com os clientes é o foco do chamado marketing de relacionamento. Neste sentido, se a empresa conseguir praticá-lo, há uma grande possibilidade de se ter clientes retidos e, até mesmo leais, e consequentes benefícios desse relacionamento, como, por exemplo, clientes menos sensíveis a preços, aumento do volume de negócios, do lucro e da rentabilidade das empresas. Talvez por isso, a retenção de clientes seja defendida, atualmente, como um dos principais fatores de sucesso empresarial (LIN; WU, 2011; HELM, 2007) como abordado na sequência para a composição da relação deste ensaio teórico.

\section{Retenção de Clientes e as Táticas Vinculantes}

Um consumidor torna-se um cliente fiel por força da oferta de produtos e serviços moldados, cuidadosamente, para as suas necessidades, ao contrário do passado, onde era o cliente que deveria moldar-se ao fornecedor 
(McKENNA, 1999). Atualmente, com uma concorrência intensa e consumidores bem informados, torna-se cada vez mais necessário encontrar maneiras de desenvolver uma relação de longo prazo com seus clientes, com objetivo de isolar os melhores deles das ofertas da concorrência (RUST; ZEITHAML; LEMON, 2001; GUPTA et al., 2006).

Assim, a retenção de clientes está direcionada para que as empresas focalizem esforços de marketing nos clientes existentes, concentrando-se em satisfazer os clientes atuais ao invés de apenas conquistar novos clientes. A intenção de tudo isso é conquistar o cliente para que este permaneça vinculado à empresa em uma perspectiva de longo prazo (TRASORRAS; WEINSTEIN; ABRAT'T, 2009; HOFFMAN; BATESON, 2003; REICHHELD; MARKEY Jr.; HOPTON, 2000). Em virtude disso, a retenção de clientes já está sendo indicada como uma medida relevante de desempenho econômicofinanceiro que retrata o sucesso global de um negócio (HELM, 2007). Segundo Reichheld (1996), a retenção de clientes é a válvula central que integra todas as dimensões de uma empresa e mede seu desempenho na criação de valor para seus clientes.

A retenção de clientes está fortemente relacionada à repetição de negócios com um fornecedor preferencial (RUST; ZAHORIK, 1993; VAVRA; PRUDEN, 1995). Portanto, a retenção de clientes pode ser definida como a capacidade de atender os clientes atuais, motivando-os a repetirem compras no futuro de forma sistemática (AURIER; N'GOALA, 2010). Cabe ressaltar que, de acordo com Oliver (2010), a retenção de clientes também pode ser compreendida como uma construção de atitude, a qual reflete o apego emocional e psicológico inerente ao relacionamento entre os parceiros de troca. Além disso, a retenção de clientes não está relacionada apenas a comportamentos definitivos, mas também há indicativos da direção provável de comportamentos futuros, o que pode auxiliar os gestores a definirem suas estratégias, ações e investimentos de forma mais assertiva (ROOS; GUSTAFSSON, 2007).

Para Grönroos (2009), fidelidade ou lealdade não significa somente que o cliente deve manter-se fiel à empresa, mas que a empresa também deve manter-se fiel ao cliente, este modo de pensar mútuo, desenvolve com o tempo. Lovelock (2006), por sua vez, entende que a lealdade ou a fidelidade é a disposição de um cliente para continuar a prestigiar uma empresa a longo prazo, é comprar e utilizar seus serviços repetidamente, dar preferência, com exclusividade e recomendar seus serviços e produtos aos seus colegas, contudo fidelidade abrange preferência, afeição e intenção futura. Segundo Reichheld (1996), a lealdade é um dos principais impulsionadores para o aumento da performance e do sucesso empresarial. Conforme Grönroos (2009) e Trasorras, WeinsteineAbratt (2009), para que a empresa crie uma lealdade com os clientes, ela deve atendê-los de tal maneira, que eles percebam que podem confiar na empresa em todos os aspectos, o tempo todo.

De acordo com Kotler (2005), existem basicamente duas maneiras de fortalecer a retenção dos clientes. A primeira delas é criando uma barreira que impeça os clientes de uma possível troca: caso envolva alto custo de capital, os clientes ficam menos propensos à mudança. A outra maneira é entregando um alto grau de satisfação ao cliente, dificultando para o concorrente ultrapassar as barreiras as mudanças simplesmente oferecendo preços mais baixos ou alguns incentivos. O fortalecimento da retenção de clientes é, portanto, decorrente de diversas atitudes que ocorrem durante o relacionamento entre as empresas e seus clientes. Diante disso, diversos pesquisadores têm reunido esforços no sentido de tentar compreender esse fenômeno. Por exemplo, sustentam que o amadurecimento do relacionamento empresa-cliente ocorre por meio de três táticas vinculantes, quais sejam, as táticas sociais, as financeiras e as estruturais (BERRY; PARASURAMAN, 1991).

As táticas vinculantes sociais resultam de componentes de natureza emocional ou afetiva, como familiaridade, amizade e confiança na troca interpessoal, além de outros elementos, como boas relações entre empregados e clientes, eventos especiais e tratamento personalizado (RODRIGUEZ; WILSON, 2002; WENDLANT; SCHRADER 2007). Já as táticas financeiras levam em consideração os sistemas financeiros de risco e recompensa que são avaliados pelos clientes na relação com a empresa, bem como o potencial das recompensas oferecidas para balancear os custos econômicos percebidos. Também podem existir custos significativos em terminar uma relação, especialmente na ausência de alternativas válidas, e custos de dissolução ou troca elevados, servindo como elemento de incentivo à manutenção do relacionamento (DWYER ET AL., 1987; WENDLANT; SCHRADER, 2007). 
Finalmente, as táticas vinculantes estruturais são aquelas relativas à estrutura, à administração e à institucionalização de normas em um relacionamento. São as regras, políticas, procedimentos, infraestrutura, ou acordos que fornecem estrutura formal de uma relação, além das normas e rotinas que informalmente governam a interação. Ainda, são os sistemas organizacionais e tecnologias que permitem ou facilitam a interação através de laços psicológicos, legais e físicos entre as partes, tornando difícil para o cliente considerar outros parceiros de trocas (LIANG; WANG, 2008; RIZAL; BUTTLE, 2001). Logicamente que, orientar uma empresa à retenção de clientes implica na obtenção de informações sobre o foco da alocação de recursos para o gerenciamento dos relacionamentos existentes, os quais devem ser baseados em seu valor, em uma perspectiva de longo prazo, visando, portanto, a manutenção dos clientes (ARNOLD; FANG; PALMATIER, 2011). Dessa forma, é possível que, um elevado nível de retenção de clientes conduza a um conhecimento mais aprofundado da carteira de clientes, permitindo um aperfeiçoamento dos relacionamentos existentes e a identificação de oportunidades de agregação de valor para ambas as partes (VERHOEF, 2003).

De acordo com essa premissa, os impactos de diferentes esforços de relacionamento realizados pelas empresas afetam positivamente as atitudes $\mathrm{e}$ o comprometimento dos clientes, incentivando o comportamento leal em um ciclo de reciprocidade, e consequentemente um incremento na retenção de seus clientes (LIANG; WANG, 2008). A lealdade é a demonstração que um cliente recompra um produto, uma marca ou um serviço, podendo haver também a recomendação para outros clientes. Pesquisas indicam que um dos mais fortes aspectos para a manutenção de relações duradouras que formam a base da lealdade do consumidor é a satisfação (GARBARINO; JOHNSON, 1999; OLIVER, 1997). A satisfação é, portanto, um dos principais antecedentes da lealdade dos clientes, pois estar satisfeito influencia positivamente a intenção de recomendação e recompra. Sendo assim, a lealdade do consumidor é formada basicamente pela dimensão comportamental representada pelas compras repetidas, recomendação e indicação para outros clientes (LARÁN; ESPINOZA, 2004).

Nesta perspectiva, após analisar os pressupostos teóricos, do capital intelectual com a retenção de clientes a partir das táticas vinculantes, foram identificadas possíveis relações entre duas das três táticas vinculantes: nas táticas vinculantes sociais e estruturais, excluindo assim possíveis relações do capital intelectual com as táticas vinculantes financeiras. Da mesma forma, foram identificadas relações entre o capital relacional, nos elementos de lealdade e satisfação dos clientes e o capital humano, no elemento da satisfação, com a retenção de clientes, expostas a seguir.

Nas relações entre capital intelectual e as táticas vinculantes sociais, pode-se constatar que: i) Táticas vinculantes sociais resultam de componentes de natureza emocional ou afetiva, como familiaridade, amizade e confiança na troca interpessoal, além de outros elementos, como boas relações entre empregados e clientes, eventos especiais e tratamento personalizado. (RODRIGUEZ; WILSON, 2002; WENDLANT; SCHRADER, 2007); ii) Estão alinhados com Edvinsson e Malone (1998) ao afirmarem que o capital intelectual é a posse dos conhecimentos, das experiências aplicadas e tecnologias organizacionais, relacionamentos com clientes e habilidades profissionais que proporcionam à empresa uma vantagem competitiva no mercado em que atuam.

Nas relações entre capital intelectual e as táticas vinculantes estruturais pode-se constatar que: i) As táticas vinculantes estruturais são aquelas relativas à estrutura, à administração e à institucionalização de normas em um relacionamento. São as regras, políticas, procedimentos, infra-estrutura, ou acordos que fornecem estrutura formal de uma relação, além das normas e rotinas que informalmente governam a interação. Ainda, são os sistemas organizacionais e tecnologias que permitem ou facilitam a interação através de laços psicológicos, legais e físicos entre as partes, tornando difícil para o cliente considerar outros parceiros de trocas. (LIANG; WANG, 2008; RIZAL; BUTTLE, 2001); ii) Esta relação está alinhada, conforme define Brooking (1996) com a combinação de ativos intangíveis, fruto das mudanças nas áreas de tecnologia da informação e nos meios de comunicação e também com Grant (1996), que em seus estudos comenta que existem várias abordagens de pesquisa que consideram conhecimento como uma questão central: a aprendizagem organizacional, gestão da tecnologia, e cognição; iii) Esta relação está alinhada às definições de Edvinsson e Malone (1998), onde o capital intelectual 
é a posse do conhecimento, das experiências aplicadas e tecnologias organizacionais, relacionamentos com clientes e habilidades profissionais que proporcionam à empresa uma vantagem competitiva no mercado em que atuam; iv) Esta relação está alinhada aos conceitos de Sveiby (1998) que considera as pessoas como únicos e verdadeiros agentes na empresa e que os ativos tangíveis e intangíveis são resultado das ações humanas que criam as estruturas internas e externas; v) Esta relação está alinhada segundo Bontis (2001), que comenta em seus estudos que capital humano é considerado como um dos componentes do capital intelectual e concebe o conjunto das competências, inovações, valores, cultura organizacional, políticas e filosofias de trabalho e; vi) Esta relação está alinhada, conforme Ordanini e Parasuraman (2011), que propõem que as competências de colaboração, capacidade dinâmica de orientação para o clientes e interfaces de conhecimento são fatores chave para as organizações.

Nas relações entre o capital relacional, nos seus elementos de lealdade e satisfação dos clientes e o capital humano, no seu elemento da satisfação, conforme Pereira (2004), que estão alinhados com a Retenção de Clientes, organizaram-se as seguintes constatações: i) Nos impactos de diferentes esforços de relacionamento realizados pelas empresas afetam positivamente as atitudes e o comprometimento dos clientes, incentivando o comportamento leal em um ciclo de reciprocidade, e consequentemente um incremento na retenção de seus clientes (LIANG; WANG, 2008); ii) A lealdade é a demonstração que um cliente recompra um produto, uma marca ou um serviço, podendo haver também a recomendação para outros clientes. Pesquisas indicam que um dos mais fortes aspectos para a manutenção de relações duradouras que formam a base da lealdade do consumidor é a satisfação (GARBARINO; JOHNSON, 1999; OLIVER, 1997); iii) A satisfação é, portanto, um dos principais antecedentes da lealdade dos clientes, pois estar satisfeito influencia positivamente a intenção de recomendação e recompra. Sendo assim, a lealdade do consumidor é formada basicamente pela dimensão comportamental representada pelas compras repetidas, recomendação e indicação para outros clientes (LARÁN; ESPINOZA, 2004).

\section{Proposição das Relações}

Com base nos achados da pesquisa, sugeriu-se um framework, conforme figura 3, que poderá servir de base para estudos futuros, como por exemplo, identificar quantitativamente, por técnica de análise multivariada de dados, hipóteses com seus efeitos mediadores e moderadores.

Sendo o capital intelectual subdividido conforme a literatura em capital relacional, capital estrutural e capital humano, como fatores predisponentes a retenção de clientes, por meio da ferramenta de framework desenvolvida, pode-se avaliar o impacto das táticas vinculantes sociais (natureza emocional ou afetiva), táticas vinculantes estruturais (estrutura e institucionalização de normas no relacionamento) e táticas vinculantes financeiras (sistemas financeiros), permeados pela lealdade e satisfação do cliente, nos ativos da empresa.

A partir da proposta apresentada na figura 3, tem-se um modelo estrutural para a mensuração dos aspectos relacionados ao capital intelectual e seu impacto na retenção de clientes de forma simples, mas adequado à aplicação prática. Percebe-se, também, que o capital relacional e o capital humano estão, diretamente, relacionados à retenção de clientes, como referenciado na literatura, o relacionamento empresa e cliente constitui um diferencial competitivo à empresa, sendo a satisfação do cliente primordial para o alcance da retenção e sucesso empresarial.

Trata-se de uma proposição de um esquema estrutural entre as relações e os elementos do capital intelectual, e suas subdivisões, em humano, estrutural e relacional, como recurso para a retenção de clientes, segundo as táticas vinculantes sociais e estruturais. Torna-se importante ressaltar que, em no primeiro momento, este modelo se limita a apresentar as possíveis relações conceituais, sem verificar se as relações foram totalmente ou parcialmente validadas, ou, ainda, invalidadas. A intenção de apresentar o esquema foi o de propor, compreender e instigar discussões sobre sua estrutura, suas relações e suas variáveis. 
Figura 3 . Proposta de um framework

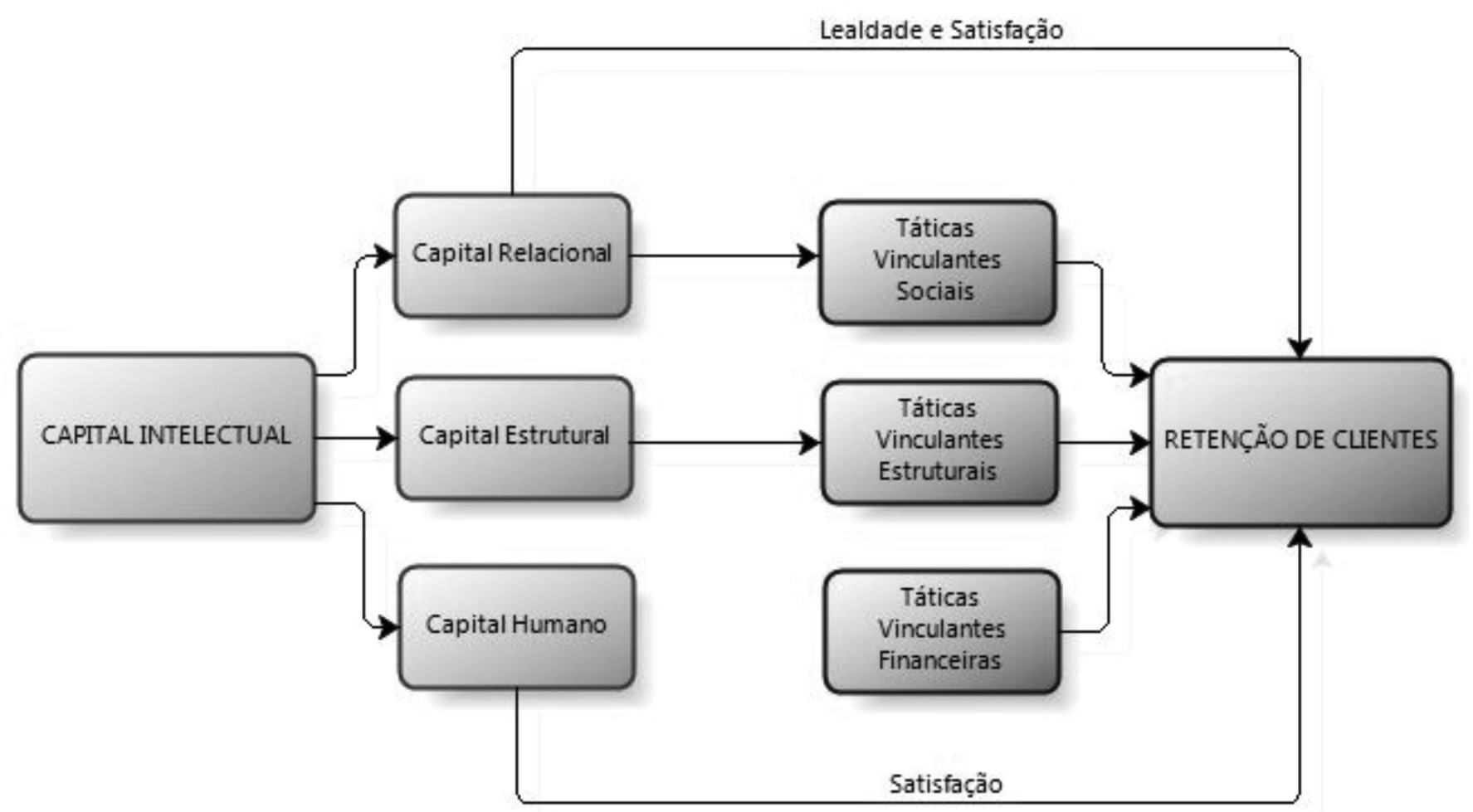

Fonte: Desenvolvido pelos autores.

Procurou-se, a partir da presente discussão, explorar as dimensões do capital intelectual, como elemento dos ativos do conhecimento e as suas relações com a retenção de clientes, estimulando a comunidade acadêmica a um maior aprofundamento dos conhecimentos sobre os ativos intangíveis, e, as suas relações com a retenção de clientes procurando evidenciar a inter-relação dos diversos fatores inerentes ao capital intelectual que impactam na retenção de clientes.

A relevância da pesquisa está contida no desenvolvimento teórico de um modelo para a avaliação do impacto do capital intelectual sobre a retenção de clientes, levando em conta todos os aspectos relacionados e essa dimensão - capital relacional, capital estrutural e capital humano - e suas estratégias de abordagem dentro da empresa, proporcionando espaço para a discussão de novos modelos, aplicáveis à diferentes realidades empresariais e o aprofundamento dos aspectos envolvidos no processo.

\section{Considerações Finais}

Em uma economia baseada no conhecimento, existe uma crescente importância do capital intelectual, no contexto atual, da identificação de sua natureza, mensuração e principais características. A pesquisa evidenciou o capital intelectual como recurso gerador de benefícios por meio de sua criatividade, habilidade e competência dos indivíduos, tais como funcionários, clientes e fornecedores e a serem utilizadas na retenção dos clientes, a partir da utilização das táticas vinculantes sociais e estruturais. A intensidade destas influências pode variar em função da estrutura e dos investimentos em treinamentos realizados pelas organizações em seus diferentes patamares e atividades econômicas.

Ao mesmo tempo, no que tange a perspectiva contábil, identifica-se uma subjetividade inerente ao mensurar esse capital intelectual o que sugere a proposição de esquema estrutural que dimensione essas relações. Nesta 
perspectiva o capital intelectual é observado com um recurso controlado pela entidade como resultado de eventos passados e do qual se espera que resultem em futuros benefícios econômicos que são o potencial do recurso em contribuir para a geração de caixa ou equivalentes. Assim perceber-se que ao se dar atenção ao capital intectual, a organização pode obter melhores resultados financeiros.

Como possíveis formas de mensurar o capital intelectual com a utilização de informações contábeis, pode-se analisar valores de algumas contas ou variações dos valores de um exercício para o outro, como possível indicador. O capital humano pode ser avaliado pelo valor gasto com os funcionários, o capital estrutural pode ser avaliado pelos valores dos ativos intangíveis e o capital relacional pode ser o valor da carteira de clientes da empresa. Além disso, outras métricas contábeis e financeiras poder ser utilizadas para também servir de indicadores para mensurar o capital intelectual utilizando-se da influência das táticas vinculantes sociais e estruturais, pois, pode-se depender do planejamento estratégico da organização, deste que este esteja orientado para o desenvolvimento do conhecimento.

O objetivo deste ensaio teórico foi de articular, a partir de uma revisão dos pressupostos teóricos as relações entre os elementos do capital intelectual, ou seja, humano, estrutural e relacional, com a retenção de clientes segundo as tipologias das táticas vinculantes, dissociadas em sociais, financeiras e estruturais a fim de estabelecer um esquema estrutural que servisse de base para incentivar a aplicabilidade empírica, através, da utilização de técnicas de análise multivariada de dados, propiciando, assim, um aperfeiçoamento nas pesquisas que lidam com a subjetividade desta mensuração, como observado nas mensurações contábeis tradicionais. Identificou-se, neste processo de análise teórica, que o capital relacional e o capital humano estão, diretamente, relacionados à retenção de clientes, intercedidos pelas táticas vinculantes, e, consequentemente, propensos a obtenção de vantagem empresarial.

Em termos de perspectivas para estudos futuros, além de ampliar as relações propostas entre o capital intelectual e a retenção de clientes, é possível que, por exemplo, em dado momento a retenção de clientes possa passar de consequência do capital intelectual, para antecedente deste mesmo.
Procurou-se, a partir da presente discussão, explorar as dimensões do capital intelectual, como elemento dos ativos do conhecimento e a suas relações com a retenção de clientes, instigando a comunidade acadêmica a um maior aprofundamento dos conhecimentos sobre os ativos intangíveis e a suas relações com a retenção de clientes procurando evidenciar a sua relação com as táticas vinculantes sociais e estruturais.

\section{Referências Bỉbliográficas}

ARNOLD, T. J.; FANG, E.; PALMATIER, R. W. The effects of customer acquisition and retention orientations on a firm's radical and incremental innovation performance. Journal of the Academic Marketing Science, v. 39, p. 234-251, 2011.

AURIER, P.; N'GOALA, G. The differing and mediating roles of trusdt and relationship commitment in service relationship maintenance and development. Journal of the Academic Marketing Science, v. 38, p. 303-325, 2010.

BAIRI, J.; MANOHAR, B. M. Critical success factors in gaining user customer satisfaction outsourced IT services. Journal of Enterprise Information Management. v. 24, n.6, p. $475-493$.

BENGOA, D. S.; KAUFMANN, H. R. Questioning western knowledge transfer methodologies: toward a reciprocal and intercultural transfer of knowledge. Thunderbird International Business Review. v. 56, n.1, p.11-26, 2014.

\section{BERRY, L.L.; PARASURAMAN, A. Marketing} Services-Competing Through Quality, New York, The Free Press. 1991.

BOISOT, M. H. Knowledge assets: securing competitive advantage in the information economy. New York. Oxford University Press, 1998.

BONTIS, N. Assessing knowledge assets: a review of the models used to measure intellectual capital. International Journal of Management Reviews.v.3, n. 1, p. 41-60, 2001.

BROOKING. A. El capital intelectual. $1^{\mathrm{a}} \mathrm{ed}$. Barcelona: Editora Pai dós, 1996.

CANNON, Joseph P.; PERREAULT JR., William D. Buyer-seller relationships in business markets. 
Journal of Marketing Research, v. 36, n. 4, p. 439460, 1999.

DAVENPORT, T. H.; PRUSAK, L. Conhecimento empresarial: como as organizações gerenciam o seu capital intelectual. $4^{a}$ ed. Tradução de Lenke Peres. Rio de Janeiro: Campus, 1998.

DEN HERTOG, B.; VANDER, A. A.; DE JONG, W. Capabilities for managing service innovation: Towards a conceptual framework. Journal of Service Management. v. 21, n.4, p. 490-514, 2010.

DRUKER, P. F. The age of discontinuity: guidelines to our changing society. New York. Harper and Row. 1969.

DWYER, R.F.; SCHURR, P.H.; OH, S. Developing buyer-seller relationships. Journal of Marketing, v. 51, n. 2, p.11-27, 1987.

\section{EDVINSSON, L.; MALONE, M. S. Capital} intellectual. São Paulo: Makron Books, 1998.

ERICSON, S. G.; ROTHBERG, H. N. Intellectual capital and competitiveness: guidelines for policy. Competitiveness Review.v.10, n. 2, p.192-198, 2000.

GARBARINO, E.; JOHNSON, M. The different roles of satisfaction, trust and commitment for relational and transactional consumers. Journal of Marketing, n. 63, p. 70-87, 1999.

GRANT, R. Toward a knowledge-based theory of the firm. Strategic Management Journal.v.17, p. 109-122, 1996.

GRÖNROOS, C. Marketing: gerenciamento e serviços. 3. ed. Rio de Janeiro: Elsevier, 2009.

GROPP, B. M. C; TAVARES, M. G. P. Dimensões intangíveis: a relevância do conhecimento tácito em processos de inovação e sustentabilidade. $\mathbf{6}^{\mathbf{a}}$ Conferência Internacional sobre Inovação e Gestão, Pontifícia Universidade Católica de São Paulo, 2009.

GUPTA, S.; LEHMANN, D. R.; STUART, J. A. Valuing customers. Journal of Marketing Research, v. 41, n. 1, p. 7-18, 2004.

GUPTA, S.; HANSSENS, D.; HARDIE, B.; KAHN, W. V.; LIN, N.; RAVISHANKER, N.; SRIRAM, S. Modeling customer lifetime value. Journal of
Service Research, v. 9, n. 2, p. 139-155, 2006.

HELM, S. The role of corporate reputation in determining inventor satisfaction and loyalty. Corporate Reputation Review, v. 10, n. 1, p. 22-37, 2007.

HENNIG-THURAU, T.; GWINNER, K. P.; GREMLER, D. D. Why customers build relationships with companies and why not. In: HENNIG-THURAU, T.; HANSEN, U. Relationship marketing: gaining competitive advantage through customer satisfaction and customer retention. Berlin: Springer Verlag. p. 369$391,2000$.

HENNIG-THURAU, T.; GWINNER, K. P.; GREMLER, D. D. Understanding relationship marketing outcomes: an integration of relational benefits and relationship quality. Journal of Service Research, v. 4, n. 3, p. 230-247, 2002.

HOFFMAN, K. D.; BATESON, J. E. G. Princípios de Marketing de Serviços - Conceitos, Estratégias e Casos. São Paulo: Pioneira Thomson Learning, 2003.

JOHNSON, M.D.;SELNESF.

Customer Portfolio Management:

Toward a Dynamic Theory of Exchange Relationships, Journal of Marketing, v. 68, p. 117, 2004.

KHALIQUE, M.; SHAARI, J. A. N. B.; ISA A. H. B. M. The road to the development of intellectual capital theory. International Journal of Learning and Intellectual Capital. v. 10, n.2, p. 122-136, 2013.

KOTLER, Philip. Marketing essencial: conceitos, estratégias e casos. São Paulo: Prentice Hall, 2005.

LARÁN, J. A.; ESPINOZA, F. S. Consumidores satisfeitos, e então? Analisando a satisfação como antecedente da lealdade. Revista de Administração Contemporânea, v. 8, n. 2, p. 51-70, 2004.

LIANG, J.; WANG, W. Do loyal and more involved customers reciprocate retailer's relationship efforts? Journal of Services Research. v. 8, n. 1, p. 63-90, 2008.

LIN, J. C.; WU, C. The role of expected future use in relationship-based service retention. Managing Service Quality, v. 21, n. 5, p. 535-551, 2011. 
LÓPEZ-RUIZ, V. R.; ALFARO-NAVARRO, J. L.; NEVADO-PENA, D. Knowledge city index construction: An intelectual capital perspective. Expert Systems with Applications. v. 41, n.12, p. 5560-5572, 2014.

LOVELOCK, C. Marketing de serviços: pessoas, tecnologia e resultados. 5. ed. São Paulo: Pearson / Prentice Hall, 2006.

MACHLUP, F. Theories of the firm: marginalist, behavioral, managerial. American Economic Review. v. 57, n.1, p. 1-33, 1967.

MALHOTRA, Y. Measuring knowledge assets of a nation: knowledge systems for development. United Nations Headquarters. New York, 2003.

MANUAL DE OSLO. Diretrizes para coleta e interpretação de dados sobre inovação. Terceira Edição, FINEP, OECD, 1997.

McKENNA, Regis. Competindo em tempo real: estratégias vencedoras para era do cliente nunca satisfeito. 4. ed. Rio de Janeiro: Campus, 1999.

MORGAN, R. M.; HUNT, S. D.The commitmenttrust theory of relationship marketing. Journal of Marketing, v. 58, n. 3, p. 20-38, 1994.

NONAKA, I.; TAKEUCHI, H.The knowledgecrating company: how japanese companies create the dynamics of innovation. New York: Oxford University Press, 1995.

OLIVER, R. L. A cognitive model of the antecedents and consequences of satisfaction decisions. Journal of Marketing Research, v.17, p.460-69, 1997.

OLIVER, R. L. Satisfaction: a behavioral perspective on the consumer. New York: M. E. Sharpe, 2010.

ORDANINI, A.; PARASURAMAN, A. Service innovation viewed through a service-dominant logic lens: a conceptual framework and empirical analysis. Journal of Service Research, v.14, n. 1, p. 3-23, 2011.

PEREIRA, M. S.; FIÚSA, J. L. A.; PONTE, V. M. R. Capital intelectual e mensuração: um estudo de caso em uma empresa de telecomunicação.

RevistaContabilidade e Finanças -FEAUSP.2004.
PETRICK, J. F. The roles of quality, value, and satisfaction in predicting cruise passengers' behavioral intentions. Journal of Travel Research, v. 42, p. 397-407, 2004.

POLANYI, M. The tacit dimension. London: Routdedge\&Kegan Paul, 1966.

REICHHELD, F. F. Learning from customer defections. Harvard Business Review, v. 74, n. 2, p. 56-69, 1996.

REICHHELD, F. F. A estratégia da lealdade: a força invisível que sustenta crescimento, lucro e valor. Rio de Janeiro: Campus, 1996.

REICHHELD, F. F.; MARKEY Jr.; R. G.; HOPTON, C. The loyalty effect: the relationship between loyalty and profits. European Business Journal, v. 12, n. 3, p. 134-139, 2000.

RIZAL, A.; BUTTLE, F.. Retaining business customers through adaptation and bonding: A case study of HDOX. The Journal of Business \& Industrial Marketing. v. 16, n. 7, p. 553-573, 2001.

RODRIGUEZ, C.M.; WILSON, D.T. Relationship bonding and trust as a foundation for commitment in U.S.-Mexican strategic alliances: A structural equation modeling pproach. Journal of International Marketing. v. 10. n. 4, p. 53-76, 2002. ROOS, I.; GUSTAFSSON, A. Understanding Frequent Switching Patterns - a Crucial Element in Managing Customer Relationships, Journal of Service Research. v. 10, n. 1, p. 93-108, 2007.

RUST, R. T.; ZAHORIK, A. J. Customer satisfaction, customer retention, and market share.Journal of Retailing, v. 69, n. 2, p. 193-215, 1993.

RUST, R. T.; ZEITHAML, A. V.; LEMON, N. K. O valor do cliente: o modelo que esta reformulando a estratégia corporativa. Porto Alegre: Bookman, 2001.

SENKER, J. Tacit knowleadge and models of innovation.Oxford Journals Industrial and Corporate Change. v. 4, p 425-447, 1995.

SEQUEIRA, B. D.; SERRANO, A. M.; MARQUES, J.F. Organisational knowledge management: Three case studies in the hospitality industry. ECKM 2012 - Proceedings of the European Conference on Knowledge.p. 1505 - 1515, 2012. 
SPENDER, J. C. Making knowledge the basis of a dynamic theory of the firm.Strategic Management Journal. v. 17, p. 45-62, 1996.

STEWART, T. A. Capital intelectual: a nova vantagem competitiva das empresas. 11. ed. Rio de Janeiro: Campus, 1998.

SVEIBY, K. A nova riqueza das organizações.Rio de Janeiro: Campus, 1998.

TRASORRAS, R.; WEINSTEIN, A.; ABRAT'T, R. Value, satisfaction, loyalty and retention in professional services. Marketing Intelligence $\boldsymbol{\&}$ Planning, v. 27, n. 5, p. 615-632, 2009.

TREVIÑO, G. O. Intelligence capital: managing adaptive capabilities through agent based simulation. 2012. 125 f. Tese (Doutorado em Informação, Tecnologias e Comunicações) Instituto Tecnológico de Estudos Superiores de Monterrey, Programa em Mecatrônica e Informações Tecnológicas.

VAVRA, T. G.; PRUDEN, D. R. Using after marketing to maintain a customer base. Discount Merchandiser, v. 35, n. 5, p. 86-88, 1995.

VERHOEF, P. C. Understanding the effect of customer relationship development. Journal of Marketing, v. 67, n. 4, p. 30-45, 2003.

WALTHER, S.; SARKER, S.; SEDERA, D.; EYMANN, T. Exploring subscription renewal intention of operational cloud enterprise systems - A social-technical approach. ECIS 2013 Proceedings of the $21^{\text {st }}$ European Conference on Information Systems, p. 2134 - 2151, 2013.

WENDLANT, M.; SCHRADER, U. Consumer reactance against loyalty programs. Journal of Consumer Marketing, v. 25, n. 5, p. 293-304, 2007. 